\title{
Using Interviews \\ in Development Programs for Beginning Teachers
}

\section{Lawrence T. McGill}

Northwestern University

\section{James M. Shaeffer}

University of Wyoming

Persuading teachers to participate in programs and activities designed to improve teaching effectiveness is a persistent problem faced by teacher development co-ordinators (Geis and Smith, 1979). Designing workable development programs for beginning teachers, in particular, is especially challenging and critical. In what follows, we attempt to make the case for using semi-structured interviews with beginning teachers, both to gather information concerning their views on teaching and to initiate contact with them on behalf of a teacher/GTA Development Program.

\section{THE ADVANT AGE OF THE BEGINNING TEACHER}

Beginning teachers are in a unique and advantageous position with respect to the task of effecting successful interactions with their students, in that they were not long ago (and in many cases still are) students themselves. They know, really know, what it's like to be a student out there in a classroom listening to a teacher.

Unfortunately, when students become teachers they may spend virtually all their time trying to learn what they conceive to be the "role of the teacher," while ignoring the fact that teaching is really about reaching students! They're so busy trying to become "teachers" (e.g., by emulating other teachers, 
by focusing solely on materials and methods while forgetting about student needs, etc.) that they fail to do the job of facilitating student learning.

Compounding the problem, by the time most students enter graduate school they have largely internalized the same values and attitudes about teaching that most older faculty members hold (Bess, 1978). That is, they think of teaching as a "task" that must be performed and then set aside, so they can get on with their research interests.

Recent research, however, indicates that beginning teachers can be influenced to modify their attitudes about teaching if intervention occurs early enough in their teaching careers. In spring 1983, the authors conducted an interview study of graduate teaching assistants (GTAs) at a large private university in the Midwest. Our results support the optimistic position that beginning teachers are, in fact, on the right track with respect to many of their initial ideas about teaching. Here are some of our major findings:

(1) Beginning teachers pay close attention to student feedback in evaluating their own teaching performance;

(2) They express great concern about the quality of their presentations to students;

(3) They point to experiences with students as what stands out for them in their experience as teachers;

(4) They want training in how to meet student needs (if they want training at all); and

(5) They seek to create a "comfortable" learning environment for students through the use of humor, excitement, and stimulating interaction (McGill, Shaeffer and Menges, 1984).

All of this leads us to believe that, despite institutional pressures that de-emphasize the importance of teaching relative to research, new teachers want to and do take teaching seriously. Development programs are well advised to reinforce the essentially "correct" ideas about teaching that beginning teachers already seem to possess. We suggest that the interview can serve as an important vehicle for such reinforcement. 


\section{THE CASE FOR THE INTER VIEW}

One of the things that struck us during our study was that GTAs really seemed to enjoy talking with us about teaching. The excitement that the interviews seemed to elicit suggested to us that interviews might also be useful as tools in teacher development programs. GTAs, we noticed, seemed more willing to talk about teaching in a one-on-one situation than in a group of their peers, although participating in the interviews also tends to lay a nice foundation for subsequent group discussions in seminars on teaching. The interview also boasts the following important advantages as part of a beginning teacher development program:

1) Interviews recognize the teacher's particular situation. While teachers share many traits in common as members of the same profession, all teachers nevertheless differ from each other in important respects. In addition, all teaching situations are in some sense unique. In order to identify the needs of beginning teachers in the particular teaching situations in which they find themselves, we need at some point to ask them what they need.

2) New teachers feel tentative at times. The interview, if it focuses upon experiences teachers have had prior to teaching, can point out to them that they in fact have skills (that they may not know they had) that they can bring to bear in teaching.

As sociologist Erving Goffman points out:

When the individual [moves] into a new position in society and obtains a new part to perform, he is not likely to be told in full detail how to conduct himself, nor will the facts of his new situation press sufficiently on him from the start to determine his conduct without his further giving thought to it. Ordinarily he will be given only a few cues, hints, and stage directions, and it will be assumed that he already has in his repertoire a large number of bits and pieces of performances that will be required in the new setting (Goffman, 1959, pp. 72-3).

One thing that development personnel can do, then, is to help new teachers identify which of their previous experiences may have involved the use of skills transferrable to teaching and how those skills may be transferred.

3) Change, growth, and learning all come from within. The interview encourages new teachers to begin their own 
thought processes concerning where they are and where they would like to go in their teaching.

4) The interview builds rapport. The interviewer and the interviewee have shared, in some ways, an "intimate" experience with each other that they now hold in common and which they can use as the basis for building a relationship. The new teacher now has a personal contact with a member of the teacher development staff whom they can feel free to call upon when needed.

5) The interview is not didactic. New teachers, by and large, don't recognize pedagogy as a discipline. They usually will not take steps on their own to learn about teaching. They don't take education classes, and they usually won't attend seminars. But they will, in fact, talk at great length about teaching if you ask them to.

6) As teachers, we all advocate "starting at the level of the learner." If we want to train new teachers, this point remains just as valid, even though our "students" are teachers to others. The interview allows us to assess the "level" at which new teachers stand with respect to their knowledge about teaching and enables us to design individualized training programs to meet the unique needs for training that each new teacher brings with them.

There are, of course, additional reasons to use interviews. For example, they encourage active participation rather than passive listening, they're personal instead of anonymous, and so on. In the appendix, we present a sample interview schedule (adapted from the one used on our study of GTAs) that could be used or modified for use in other teacher development programs.

\section{The Interview in the Context of an Experience-Based Development Program}

The case for the interview is based in part on a belief in the value of using personal experience as a guide for the design of teacher development programs. Let's face it--when others make suggestions about how to design development programs, we often tend to take those ideas with a grain of salt. But if we take a moment to think about our own experiences, we can (re)discover, through simple reflection, what things have worked for us. That certainty of knowing what will work, in at least 
one case, can be a good starting point for designing development programs.

To illustrate this principle with respect to the use of interviews, take a moment to reflect upon your own experiences with opinion surveys and other informal types of interviews. As you participate in an interview, it is difficult, for example, not to feel somewhat flattered that someone has taken an interest in you and your ideas. Or perhaps you've found that as you dig into your mind for answers, you sometimes display an expertise you weren't aware you possessed. Or that you've been provoked into new thoughts as a result of being asked pointblank questions you may have never seriously considered before in a systematic way.

Here is an illustration. At the beginning of the 1984 POD conference, many of us had the opportunity to get together in pairs and briefly interview each other about our expectations for the conference. This exercise revealed at least three things about the use of interviews: 1) they are good for breaking the ice with a person you don't know; 2) they enable you to learn something about someone else; and 3) they tell you things about yourself that you either may not have admitted before, or of which you may not have been fully aware. The moral here is that through interaction with another person we learn more about ourselves - more perhaps than if we had just thought about a set of questions on our own. Talking with another person forces us to deal with questions and make a solid case for our responses, which is important.

With respect to "experience-based" development programs, the point is twofold. First, to the extent that we can design development programs from principles derivable from personal past experiences, we should do so. This builds a sense of confidence into our programs that may mean the difference between success and failure. This is not to say that books, experts, or theories are never useful! Rather, we are saying that it is important not to forget that our own experiential knowledge can be helpful as well. Second, the use of interviews makes the program itself experiential, which again enhances the possibilities for its success. 


\section{INTRODUCING INTERVIEWS INTO TEACHER DEVELOPMENT PROGRAMS}

Let us suggest how the interview might fit into an overall Beginning Teacher/GTA development program. We make the following recommendations:

1) Program input. An interview with the new teacher should take place early in a program of teacher development. Doing this early sends a clear message to the beginning teacher that says: "we want your input." Give teachers a chance to teach several classes before conducting the interview, but catch them while the job is still novel enough that they are interested in both thinking about and tinkering with their approach to teaching.

2) Staff-teacher rapport. The interview should be conducted by someone who is perceived either as an "expert" or as "concerned" with teaching and learning and who feels comfortable talking about teaching with respect to the subject matter being taught by the beginning teacher. This helps to elicit responsible and searching answers to the questions being asked in the interview.

3) Feedback to teachers. If possible, some tabulating scheme should be set up so as to provide quick feedback to the interviewees (within two weeks, if possible), highlighting some of the responses given by those who participated in interviews. It might be most useful to tabulate and release short summaries of responses intermittently over the period of an academic term, so as to maintain a relatively high level of interest on the part of new teachers in issues of pedagogy throughout the term.

4) Program design. Based upon the interview responses, seminars and other programs can be designed. Advertisements for such seminars and programs can be included in the same mailings as the tabulated interview responses, which would convey the message that the institution is indeed making an attempt to be responsive to the needs of its beginning teachers.

\section{SOME NOTES ON THE MECHANICS OF THE INTERVIEWS}

Length and number of interviews: It should be noted that interviews are intensive. They require concentration if they are 
to be done well. While the schedule suggested in the appendix might successfully be completed in about twenty or thirty minutes, one person shouldn't be expected to do more than four or five on one day. As for how many interviews ought to be conducted in all, we found that considerable variance in responses was generated after ten or so interviews. As fodder for planning future teaching seminars, such a number would probably suffice. But by far the greatest value of the interview to the new teacher is realized in the process of conducting the interview itself. For this reason, only the size of the development staff should limit the number of interviews conducted.

Selection of interviewees: We selected interviewees in a very purposeful way, so that comparisons of GTAs could be made across different academic disciplines. This isn't necessary for developmental purposes, of course, but it may be important that development staffers request interviews of new teachers on a person-to-person basis. A system whereby teachers can volunteer to be interviewed might work, but some contingency plan for soliciting interviewees ought to be ready for implementation should the volunteer system fail.

Explaining the interview to the new teacher: We told GTAs we were interviewing them to find out whether the GTA development program was meeting their needs and how it might be improved. Additionally, we had academic interests in how GTAs conceptualized teaching and what they thought of their jobs as GTAs. These agendas were also made explicit in the course of the interview. Used in teacher development programs, it can be pointed out to new teachers that the interview is a way of getting to know them, of finding out who they are and what they would like to see in such a program. It can also be explained that polling teachers on their ideas about teaching enrichs the program and creates an interesting information base from which both teachers and development staff can learn.

In conclusion, we recognize that the interview is a "technique," and are mindful of the caveats Bob Tennenbaum (1984) stresses concerning our predilection for using techniques to distance ourselves from our "clients." The point we hope to make is that there can be techniques which draw people together rather than pushing them apart. The interview, if sensitively administered, seems to be such a technique. 


\section{SAMPLE INTERVIEW SCHEDULE}

1. Thinking back to your first teaching experience in higher education (or adult education), what elements of that experience stand out in your mind?

2. Prior to teaching for the first time, did you have any experiences which helped prepare you for teaching?

3. Looking back, if you could have been given any type of preparation you wanted or needed for teaching, what would that preparation entail?

4. In general, when you reach the end of a class session, how do you determine whether that session has been successful or unsuccessful?

5. Can you give me an adjective or list of adjectives that would describe your particular "style" of teaching?

6. In your own experience, can you think of someone you would characterize as a good teacher? What was he or she like?

7. In your own experience, can you think of someone you would characterize as a poor teacher? What was he or she like?

\section{REFERENCES}

Bess, J. L. (1978). Anticipatory socialization of graduate students. Research in Higher Education, 8, 289-317.

Geis, G. L. \& Smith, R. (1979). Professors' perceptions of teaching and learning: Implications for faculty development. Paper presented at the meeting of the American Educational Research Association, San Francisco.

Goffman, E. (1959). The presentation of self in everyday life. New York: Doubleday.

McGill, L. T., Shaeffer, J. M. \& Menges, R. J. (1984). How do GTAs learn to teach?: Some empirical findings. Paper presented at the Tenth International Conference on Improving University Teaching, College Park, Md.

Tennenbaum, R. (1984). Keynote address at the annual meeting of the Professional and Organizational Development Network in Higher Education, Asilomar, CA. 